\title{
A SAÚDE DO HOMEM E SUA PERCEPÇÃO SOBRE O SISTEMA PÚBLICO DE SAÚDE: A UBSF E O ATENDIMENTO AO PÚBLICO MASCULINO NO BAIRRO MORADA NOVA, UBERLÂNDIA/MG
}

\section{MAN'S HEALTH AND ITS PERCEPTION ABOUT THE PUBLICO HEALTH SYSTEM: UBSF AND THE SERVICE THE MALE PUBLIC IN THE MORADA NOVA, UBERLÂNDIA/MG}

\author{
Marcelo Firmino \\ Mestre, Universidade Federal de Uberlândia \\ marceloenf@yahoo.com.br \\ Gerusa Gonçalves Moura \\ Doutora, Universidade Federal de Uberlândia \\ gerusa.moura@ufu.br
}

\begin{abstract}
RESUMO
O homem traz consigo condições ligadas ao gênero masculino de que este não adoece, nutrindo a sensação de invulnerabilidade e a busca por serviços de saúde seria uma ação contraditória. Nesse sentido, o objetivo desta pesquisa é compreender os fatores que levam o homem a não procurar por serviços na Atenção Primária à Saúde, tendo como local de pesquisa o bairro Morada Nova, em Uberlândia/MG. Para sua realização, a metodologia baseou-se na revisão bibliográfica e na aplicação de um questionário com a população masculina na faixa etária de 20 e 59 anos, residente no território da Unidade Saúde da Família (USF) do bairro Morada Nova (Uberlândia/MG). Com a realização da pesquisa, pode-se verificar que a população pesquisada tem baixa escolaridade e é mais numerosa na faixa etária entre 30 e 49 anos. Todos os entrevistados dependem do Sistema Único de Saúde (SUS). Os serviços de prevenção e promoção à saúde são subutilizados pela população entrevistada, tanto que foi constado que houve uma pequena procura pela realização do exame de próstata. A USF do Morada Nova apresentou resolutividade satisfatória de agravos à saúde na visão dos entrevistados. As justificativas da recusa em participar de ações de saúde direcionadas a eles são: "não tenho tempo", "não tenho interesse", "trabalho", "desconheço as atividades para o homem na USF". Entretanto, o mesmo público também manifesta o desejo por atividades direcionadas exclusivamente a eles. Dessa forma, pode-se constatar que mesmo após dez anos do incremento da Política Nacional de Saúde do Homem, este ainda carece de serviços de promoção e prevenção de doenças, e os serviços da Atenção Primária de Saúde (APS) ainda não conseguem inserir o homem totalmente em seu rol de ações.
\end{abstract}

Palavras-chave: Saúde do Homem. Atenção Primária à Saúde. Promoção à Saúde do Homem.

\begin{abstract}
The man brings with him conditions linked to the male gender that he does not get sick, nurturing the feeling of invulnerability of the man and the search for health services would be a contradictory action. In this sense, the objective of this research is to understand the factors that lead the man not to seek services in Primary Health Care, having as a research site the neighborhood Morada Nova, in Uberlândia/MG. For the accomplishment of the research, the methodology was based on the bibliographical revision and an adapted questionnaire was applied with the male population in the age group of 20 and 59 years, residing in the territory of the Family Health Unit (USF) of the neighborhood Morada Nova in the city of Uberlândia/MG. With the research, it can be verified that the male population survey have low levels of education, besides being more numerous in the 30 to 49 age group. All respondents rely exclusively on SUS to meet their health needs. Man still maintains the feeling of invulnerability, prevention services and health promotion are underutilized by this population in front of it, so much that it was recorded that there was a small demand for the prostate examination. The drugs offered by SUS were not enough to satisfy all the health needs of this population. The USF of Morada Nova presented a satisfactory solution to the health of this population. The justifications for refusal to participate in directed health actions of men persist: "I do not have time", "I have no
\end{abstract}

Recebido em: 11/12/2019

Aceito para publicação em: 13/07/2020. 
interest", "work", "I do not know the activities focused on the man in USF. Even after ten years of increasing the National Health Policy of Man, it still lacks services of promotion and prevention of diseases, and APS services still can not insert man fully in his role of actions.

Key words: Men's Health. Primary Health Care. Man Health Promotion.

\section{INTRODUÇÃO}

A construção do universo masculino em seu território fornece a matriz cultural que permeia a vida em sociedade e estabelece os valores e crenças em que a sociedade se apoia. No caso específico para a saúde do homem criam-se fatores que afetam diretamente no status quo do perfil de acesso a saúde masculina.

A cultura instituída, historicamente, é de que o homem é um ser forte e que, portanto, qualquer sinal de adoecimento ou mesmo de um comportamento de cuidado com a sua saúde demonstra uma certa vulnerabilidade. A vida cotidiana do ser masculino influência na fragilização ou afastamento dos homens nas questões de autocuidado e na busca pelos serviços de saúde, seja pela organização destes serviços, que se não se adaptam a atividade laboral da população masculina, seja pela própria dinâmica individual de cada homem. Mesmo aqueles com maior nível educacional, em unanimidade, desconhecem a Política Nacional de Atenção Integral à Saúde do Homem (RODRIGUES et al., 2015).

A resistência masculina em buscar, na atenção primária o atendimento à saúde, tem reflexo no diagnóstico tardio de doenças, o que implica no agravamento da enfermidade, que passa a requer um tratamento especializado e, normalmente, de alto custo. Gomes, Nascimento e Araújo (2007) reafirma tal situação ao destacar que os homens, por se sentirem inatingíveis, tornam-se vulneráveis aos agravos de saúde, uma vez que retardam o diagnóstico precoce, consequentemente, dificultando o tratamento preventivo. Essa resistência na procura por atendimento à saúde eleva as taxas de mortalidade e morbidade por doenças que podem evitadas e, até mesmo, de doenças crônicas não transmissíveis.

Segundo Moura (2012), a mortalidade geral do Brasil, em 2010, na faixa etária dos 20 a 59 anos, foi de 3,5 por mil habitantes, sendo 2,5 vezes maior nos homens, quando comparada aos dados referentes às mulheres. Entretanto, é importante destacar que a maior causa de óbito em homens é relacionada a causas externas, que são os acidentes de trânsito, a violência e os acidente de trabalho; a segunda, às doenças do aparelho circulatório, e a terceira às neoplasias.

Diante das necessidades de saúde do homem, torna-se imperativo entender os motivos que afasta o homem dos serviços de promoção da saúde e prevenção de doenças. Identificando-se as causas que influencia negativamente o acesso a serviços de saúde, pode-se propor alguma intervenção e, consequentemente, trazer melhorias nas atividades de prevenção de doenças e promoção da saúde do homem.

Nesse sentido, o objetivo desta pesquisa é compreender os fatores que levam o homem a não procurar por serviços na atenção primária à saúde (APS), tendo como campo de estudo o bairro Morada Nova em Uberlândia/MG. Como objetivos específicos, elencamos: a) Discutir a promoção da saúde e prevenção de doenças, na saúde do homem; b) Avaliar o perfil da população masculina com relação ao seu interesse em buscar os serviços de saúde; c) Levantar os motivos que levam os homens a procurar, ou não, pelos serviços de saúde.

Para desenvolver esta pesquisa, a metodologia proposta baseou-se na aplicação de um questionário adaptado do formulário do Ministério da Saúde, intitulado "Fortalecimento da Política Nacional de Atenção Integral à Saúde do Homem" (BRASIL, 2013), com a população masculina na faixa etária de 20 e 59 anos, residente no território da Unidade Saúde da Família (USF) do bairro Morada Nova, na cidade de Uberlândia/MG.

Os participantes da pesquisa foram escolhidos por sorteio em quantidade igual nas seis micro áreas que compreendem o território da Unidade Básica de Saúde do bairro em questão. De acordo com o cadastro da USF do bairro Morada Nova, em 2018 encontrava-se nos registros o efetivo de 974 homens com idade oscilando entre 20 a 59 anos. E, por isso, optou-se por fazer uma pesquisa por amostragem populacional. 
Com a finalidade de definir a amostra populacional recorreu-se ao cálculo das populações finitas (LUIZ e MAGNANINI, 2000), onde definiu-se como amostra populacional 100 homens na faixa etária acima descrita. Os dados obtidos do questionário foram tabulados manualmente e com uso de planilha do Excel@ 2016. Foram expressos na forma de tabelas, visando identificar a ocorrência das características de incidem no homem e que repercutem na pequena procura por serviços de saúde, pela população masculina proposta, como poderá ser visto a seguir na apresentação dos resultados dessa pesquisa.

Diante disso, o trabalho será estruturado em duas partes, sendo que na primeira faz-se uma retrospectiva histórica da saúde do homem no Brasil até a instituição da Política Nacional de Atenção Integral à Saúde do Homem. Na segunda parte traça-se o perfil dos entrevistados e sua percepção em relação ao sistema de saúde público utilizado ou não por ele.

\section{A SAÚDE DO HOMEM NO BRASIL: a Instituição da Política Nacional de Atenção Integral à Saúde do Homem}

Para entender melhor como a Política Nacional de Atenção Integral à Saúde do Homem surge é importante fazer uma retrospectiva sobre a evolução do sistema de saúde no Brasil, destacando as ações do Ministério da Saúde antes da instituição do Sistema Único de Saúde (SUS) e após a sua implantação e como a saúde do homem foi tratada durante esses períodos.

No século XX, antes da existência do SUS, o Ministério da Saúde, com apoio dos estados e municípios, desenvolvia as ações de promoção e prevenção, que se davam pelas atuações no controle de endemias e vacinação, ou seja, eram condutas gerais, sem nenhum tipo de discriminação à população beneficiada. O Ministério da Saúde dispunha de poucos hospitais e os existentes eram especializados em tratar doenças psiquiátricas e tuberculose (BRASIL, 2002a).

A assistência médico-hospitalar era ofertada aos associados dos Institutos de Aposentadoria e Pensão (IAPs), criados pela Lei Eloi Chaves em 1923 para os trabalhadores urbanos de diversas categorias profissionais, como bancários, comerciários, profissionais liberais, industriários, dentre outros, ou seja, para aqueles que podiam pagar pelos serviços e, na sua maioria eram homens, já estes constituíam-se na maior parte de mão de obra da época. A assistência médico-hospitalar prestada à população definida como indigente, que não tinha nenhum direito, era executada por alguns municípios e estados, mas, principalmente, pelas instituições filantrópicas, na forma de caridade. (BRASIL, 2002a).

Os IAPs passaram por uma fusão que repercutiu na criação do Instituto Nacional de Previdência Social (INPS), Instituto de Administração da Previdência Social (IAPAS) e Instituto Nacional de Assistência Médica da Previdência Social (INAMPS). O INAMPS foi responsável pelo desenvolvimento de uma grande estrutura hospitalar de assistência à saúde que beneficiava aos trabalhadores formais ou aqueles que podiam pagar pelos serviços médico-hospitalares. Os recursos do INAMPS financiavam a sua própria rede de hospitais e ambulatórios, como também pagavam por serviços médico-hospitalar na rede privada de assistência à saúde. (BRASIL, 2002a)

Nos anos de 1970, o financiamento do INAMPS começou a entrar em crise e uma de suas medidas de economia de despesas, que passou a vigorar na década de 1980, foi contratar serviços de saúde das secretarias municipais e estaduais de saúde, por meio de convênios. Nesse mesmo período, o INAMPS aumentou a cobertura da população a serviços médico hospitalar, ao deixar de exigir a carteira de segurado para o atendimento nos hospitais próprios e conveniados da rede pública.

O Sistema Unificado e Descentralizado de Saúde (SUDS) nasceu do convênio do INAMPS com os governos estaduais, para ofertar serviços de saúde tanto à população na rede pública como na rede privada que atendia pelo INAMPS (BRASIL, 2002a). Nesse cenário, pode-se verificar que começava a se construir no Brasil um sistema de saúde com tendência à cobertura universal mesmo antes da aprovação da Lei n. 8.080 (também conhecida como Lei Orgânica da Saúde), que instituiu o Sistema Único de Saúde (SUS).

Com a criação do Sistema Único de Saúde (SUS), no ano de 1990, mudou-se o foco do modelo de saúde biomédico sanitarista, até então voltado para o tratamento de doenças, para um outro modelo, que tinha e ainda tem como princípios e diretrizes a universalização (direito aos serviços de saúde garantindo pelo Estado a todos os cidadãos), a equidade (tratamento e recursos direcionado de forma diferenciada de acordo com as necessidade de cada um) e a integralidade (garantia de um

DOl:http://dx.doi.org/10.14393/Hygeia16053468 $\quad$ Hygeia $\quad$ v.16 $\quad$ p. $105-120,2020$ página 107


conjunto de serviços de promoção à saúde, prevenção de doenças, tratamento e reabilitação). Além destes, o SUS tem também os princípios organizativos da regionalização e hierarquização, descentralização e participação popular. (BRASIL, 1994).

Com foco na descentralização e para que os municípios assumissem o papel de gestores do SUS no município, foi instaurado o Programa de Saúde Pública denominado "Saúde da Família", criado pela Portaria $n^{\circ}$ 692, de 25 de março de 1994, com a finalidade de proporcionar ações de promoção e prevenção a saúde com uma equipe composta, preliminarmente de médicos, enfermeiros, auxiliares de enfermagem e agentes comunitários de saúde, que atuariam nas comunidades. (BRASIL, 1994).

Contudo, ainda era necessário reafirmar o novo modelo de gestão a ser desempenhado pelos Municípios, Estados e União. Então, foi estabelecida a Norma Operacional Básica de 1996 (NOB 1/96), com a finalidade de delimitar deveres, gestão financeira e administrativa, ou seja, orientar o modelo de gestão do SUS. Por conseguinte, a NOB 1/96 reafirmou a necessidade de descentralização dos serviços de saúde, reorganizando o modelo assistencial dos municípios e do Distrito Federal uma vez que definiu "[...] os papéis de cada esfera de governo e, em especial, no tocante à direção única". (BRASIL, 1996, p. 7).

Em 2002, a Portaria $n^{\circ} 373$, de 27 de fevereiro, estabeleceu a "Norma Operacional de Assistência à Saúde" (NOAS, 2002b), ampliando as responsabilidades dos municípios na atenção básica e reafirmando os princípios de descentralização, regionalização e hierarquização. Além disso, definiu as ações e responsabilidades estratégicas mínimas da atenção básica a serem executadas pelo município, como salientado no Quadro 1.

Quadro 1 - Brasil: ações e responsabilidades mínimas da Atenção Básica do município, 2002

\begin{tabular}{|l|l|}
\hline \multicolumn{1}{|c|}{ Ação } & \multicolumn{1}{|c|}{ Responsabilidades } \\
\hline $\begin{array}{l}\text { Controle da } \\
\text { Tuberculose }\end{array}$ & $\begin{array}{l}\text { 1. Busca ativa de casos. 2. Diagnóstico clínico de casos. 3. Acesso a } \\
\text { exames para diagnóstico e controle: laboratorial e radiológico. 4. } \\
\text { Cadastramento dos portadores. 5. Tratamento dos casos BK+ e BK -. 6. } \\
\text { Medidas preventivas. }\end{array}$ \\
\hline $\begin{array}{l}\text { Eliminação da } \\
\text { Hanseníase }\end{array}$ & $\begin{array}{l}\text { 1, Busca ativa de casos. 2. Diagnóstico clínico de casos. 3. } \\
\text { Cadastramento dos portadores. 4. Tratamento Supervisionado dos } \\
\text { casos. 5. Controle das incapacidades físicas. 6. Medidas preventivas. }\end{array}$ \\
\hline Controle da hipertensão & $\begin{array}{l}\text { 1. Diagnóstico de casos. 2. Cadastramento dos portadores. 3.Busca } \\
\text { ativa de casos. 4. Tratamento dos casos. 5. Diagnóstico precoce de } \\
\text { complicações. 6. Primeiro Atendimento de urgência. 7. Medidas } \\
\text { preventivas. }\end{array}$ \\
\hline $\begin{array}{l}\text { Controle da Diabetes } \\
\text { Melittus }\end{array}$ & $\begin{array}{l}\text { 1. Diagnóstico de casos. 2. Cadastramento dos portadores. 3. Busca } \\
\text { ativa de casos. 4. Tratamento dos casos. 5. Monitorização dos níveis de } \\
\text { glicose do paciente. 6. Diagnóstico precoce de complicações. 7. Primeiro } \\
\text { Atendimento de urgência. 8. Encaminhamento de casos graves para } \\
\text { outro nível de complexidade. 9. Medidas preventivas e de promoção da } \\
\text { saúde. }\end{array}$ \\
\hline Saúde Bucal & $\begin{array}{l}\text { 1. Prevenção dos problemas odontológicos, prioritariamente, na } \\
\text { população de 0 a 14 anos e gestantes. 2. Cadastramento de usuários. } \\
\text { 3. Tratamento dos problemas odontológicos, prioritariamente, na } \\
\text { população de 0 a 14 anos e gestantes. 5. Atendimento a urgências } \\
\text { odontológicas. }\end{array}$ \\
$\begin{array}{l}\text { 1. Vigilância Nutricional. 2. Imunização. 3. Assistência às doenças } \\
\text { prevalentes na infância. }\end{array}$ \\
$\begin{array}{l}\text { 1. Pré-natal. 2. Prevenção de câncer de colo de útero. 3. Planejamento } \\
\text { Familiar. }\end{array}$ \\
\hline Saúde da Criança
\end{tabular}

Fonte: BRASIL, 2002b, p. 68

A regionalização da saúde deu-se por meio da criação da Região de Saúde, com polos locais com oferta de serviços de saúde hierarquizada, com ofertas de serviços da atenção primária pelo 
Município, atenção secundária pelo Estado e atenção terciária pela União (no Distrito Federal, tanto a atenção primária e a secundária são de sua responsabilidade). A NOAS (2002b) veio para aprimorar a organização do SUS, visando superar as dificuldades e os impasses provenientes da implantação do SUS. Outros programas de saúde foram postos em prática, aumentado a oferta por serviços de promoção e prevenção nos municípios, e todos eles executados pelo Programa de Saúde da Família, mas nem sempre acessível aos homens, diante das suas condições de trabalho e da própria cultura que foi se instalado ao logo dos anos sobre a saúde do homem.

O Programa Saúde da Família, desde a sua criação, já tratava de assuntos pertinentes à saúde da mulher, da criança, do idoso e de algumas doenças crônicas e degenerativas, contudo era necessário adequá-lo às carências da população, por isso, a criação do programa "A Política de Atenção Integral a Saúde da Mulher”, que, em seu plano de ação de 2004 a 2007, visava promover, dentre outras, melhores condições de vida, planejamento familiar, inclusive com a presença do homem neste quesito, e redução da morbimortalidade materna e feminina por causas evitáveis. (BRASIL, 2004b, p. 12).

Um recurso novo aplicado sob orientação dos Ministério da Saúde foi "A Política Nacional de Humanização" (PNH) do SUS, implementada em 2004, que veio com a finalidade de reafirmar o SUS na construção de políticas de saúde, tendo como prioridade o atendimento com hora marcada; redução de filas de espera; identificação dos profissionais envolvidos no atendimento; gestão participativa das unidades de saúde por usuários e trabalhadores; capacitação dos profissionais e valorização do profissional alocado nas unidades de saúde. O financiamento proposto das ações do PNH seria originado pela pactuação entre os municípios, Estado e União (BRASIL, 2004c). Essas condutas mencionadas anteriormente pretendiam melhorar o acolhimento e alavancar a participação popular, demonstrando o interesse do SUS em ofertar serviços de qualidade a população brasileira.

O extrato populacional economicamente ativo tem particularidades no que toca a sua demanda por serviços de saúde, aproveitando a bandeira da $\mathrm{PNH}$, observamos as condições de implementar ações a saúde do trabalhador. A Portaria Interministerial $n^{\circ}$ 153, de 13 de fevereiro de 2004, definiu as ações a serem empregadas visando à Saúde do Trabalhador, com o comprometimento do Ministério do Trabalho e Emprego, Ministério da Saúde e Previdência Social em promover ações sinérgicas voltadas para a saúde do trabalhador, compartilhamento de informações e ações de caráter intersetorial, garantindo o direito a segurança e à saúde do trabalhador (BRASIL, 2004a). Entretanto, essa portaria interministerial buscou superar a fragmentação, desarticulação e superposição das ações implementadas pelos setores do Trabalho, Previdência Social, Saúde e Meio Ambiente. Sendo um bom exemplo de articulação de vários setores com o fim de fornecer subsídios para conhecermos melhor a situação do trabalhador brasileiro.

O Conselho Nacional de Saúde formado pelos gestores de saúde municipais, estaduais e federal, em 2006, objetivando a descentralização, à gestão e à organização do SUS, identificaram na população brasileira a necessidade de atender prioritariamente alguns grupos populacionais, assim elaboraram "O Pacto pela Saúde", originado pela Portaria $n^{\circ} 399$, de 22 de fevereiro de 2006, que definiu as prioridades articuladas e integradas nos três componentes: Pacto pela Vida, Pacto em Defesa do SUS e Pacto pela Gestão do SUS.

Décadas após o início dos primeiros programas de atenção à saúde, o Ministério da Saúde vislumbrou as peculiaridades do perfil masculino e, assim, a Política Nacional de Saúde do Homem foi criada pela Portaria $n^{\circ} 1944$, de 27 de agosto de 2009, que;

[..] visa promover a melhoria das condições de saúde da população masculina brasileira, contribuindo, de modo efetivo, para a redução da morbidade e da mortalidade dessa população, por meio do enfrentamento racional dos fatores de risco e mediante a facilitação ao acesso, às ações e aos serviços de assistência integral à saúde (BRASIL, 2009a, p.1).

Em 2010, estimava-se que a população masculina fosse de 52 milhões para aqueles com 20 a 59 anos de idade (MOURA, 2012), o que significava que $48 \%$ da população brasileira era desassistida de um programa de saúde específico, ou seja, que contemplasse as necessidades do homem. A Política Nacional de Atenção Integral à Saúde do Homem (PNAISH) tem por diretriz central a integralidade da atenção à saúde da população masculina, em dupla perspectiva, como destaca Brasil (2009b, p. 49): 
[...] trânsito do usuário por todos os níveis da atenção, perspectiva de uma linha de cuidado que estabeleça uma dinâmica de referência e de contra-referência entre a atenção primária e as de média e alta complexidade, assegurando a continuidade no processo de atenção;

[...] compreensão sobre os agravos e a complexidade dos modos de vida e situação social do indivíduo, a fim de promover intervenções sistêmicas que abranjam inclusive as determinações sociais sobre a saúde e a doença.

O homem tem a seu desfavor todo um elemento cultural e social que interfere diretamente nos planos do SUS, quando se refere à construção de um modelo de saúde que atenda às necessidades do público masculino. Segundo Aith (2013), nota-se que é grande a importância dada à promoção da saúde no campo das políticas públicas, seja no âmbito internacional como nacional. A consolidação normativa da Política Nacional de Promoção a Saúde foi de relevância ímpar para o avanço e desenvolvimento das políticas de saúde pública no Brasil, mas uma simples edição não é condição suficiente para o cumprimento da norma legal.

O Ministério da Saúde, em conjunto com as esferas de governo federal, estadual e municipal que integram o SUS, compreenderam que é urgente melhorar os indicadores de qualidade de vida e padrões de vida mais longa e, para isso, é essencial desenvolver cuidados específicos para o homem jovem e adulto. O Plano de Atenção à Saúde do Homem objetiva, entre outras ações, mobilizar e informar especialmente os homens na da faixa etária de 20 a 59 anos sobre os cuidados com a saúde, já que estes somente procuram os serviços de saúde, quando estão doentes, o que eleva a demanda por serviços especializados de custo maior, se comparado aos serviços de saúde ofertados na atenção primária. (BRASIL, 2009b).

Para que tenhamos sucesso na elaboração de planos e metas voltados para a saúde do homem é interessante e essencial conhecer os entraves que cerceiam a oferta de saúde ao universo masculino. E para isso, como destacado anteriormente, tomamos como objeto de estudo os homens que frequentam os serviços de saúde públicos do Bairro Morada Nova em Uberlândia/MG.

\section{A SAÚDE DO HOMEM EM UBERLÂNDIA/MG: um estudo no Bairro Morada Nova}

O bairro Morada Nova está situado na região Oeste do município de Uberlândia/MG e foi criado em 1982, como sítio de recreio, numa área que ainda era definida como rural e, portanto, não estava contemplada no Plano Diretor da cidade de Uberlândia/MG daquela época. Assim, o referido bairro não dispunha, inicialmente, de serviços urbanos como: posto de saúde, água tratada, rede de esgoto, rede de água pluvial, asfalto e transporte público, dentre outras melhorias.

Em 2014 iniciaram-se os tramites para a inclusão do bairro Morada Nova no Plano Diretor do município de Uberlândia/MG. Entretanto, mesmo após ocorrer essa inclusão, o bairro ainda apresentava uma série de problemas, como a falta de coleta de esgoto, asfalto e rede de água pluvial; entretanto, dispõe de água tratada, posto de saúde, transporte público, escola estadual e municipal. A população total estimada no bairro Morada Nova é de aproximadamente, 10.000 pessoas (UBERLÂNDIA, 2014). O bairro Morada Nova dispõe de uma praça e de um campo de futebol para atividades de lazer. A participação popular da Associação dos Moradores do Bairro Morada Nova na busca de melhorias para o bairro é perene, mas uma destas ações é a sua participação assídua no Conselho de Saúde do Setor Oeste, em busca de avanços para o bairro no tocante a melhorias na saúde de sua comunidade.

Atualmente, o bairro Morada Nova possui duas equipes do Programa Saúde da Família, e os questionários foram aplicados recorrendo a área de abrangência de apenas uma dessas equipes, $o$ que resultou na aplicação de 100 questionários com a população masculina residente no bairro, cujas características sociodemográficas serão demonstradas a seguir.

Iniciou-se pela faixa etária, na qual observou uma distribuição nas quatro faixas populacionais, semelhante à divulgada na pirâmide etária absoluta do Instituto Brasileiro de Geografia e Estatística (IBGE, 2019), sendo a população de homens maior na faixa etária dos 30 aos 49 anos, conforme exibem os dados do Gráfico 1, apesar de haver uma equilíbrio entre as demais faixas etárias.

Com relação à escolaridade, encontrou-se a seguinte distribuição: 23 entrevistados (23\%) possuem apenas os Anos Iniciais do Ensino Fundamental; 46 homens (46\%) concluíram todo o Ensino Fundamental; 30 homens (30\%) o Ensino Médio e apenas 1\% possui Ensino Superior incompleto DOI:http://dx.doi.org/10.14393/Hygeia16053468 $\quad$ Hygeia $\quad$ v.16 $\quad$ p. 105-120, 2020 página 110 
(Gráfico 2). Diante dos dados pode-se verificar que a população do bairro possui baixa escolaridade, sendo que a maioria possui apenas o ensino fundamental.

Gráfico 1 - Uberlândia/MG: faixa etária dos homens entrevistados do Bairro Morada Nova, 2018

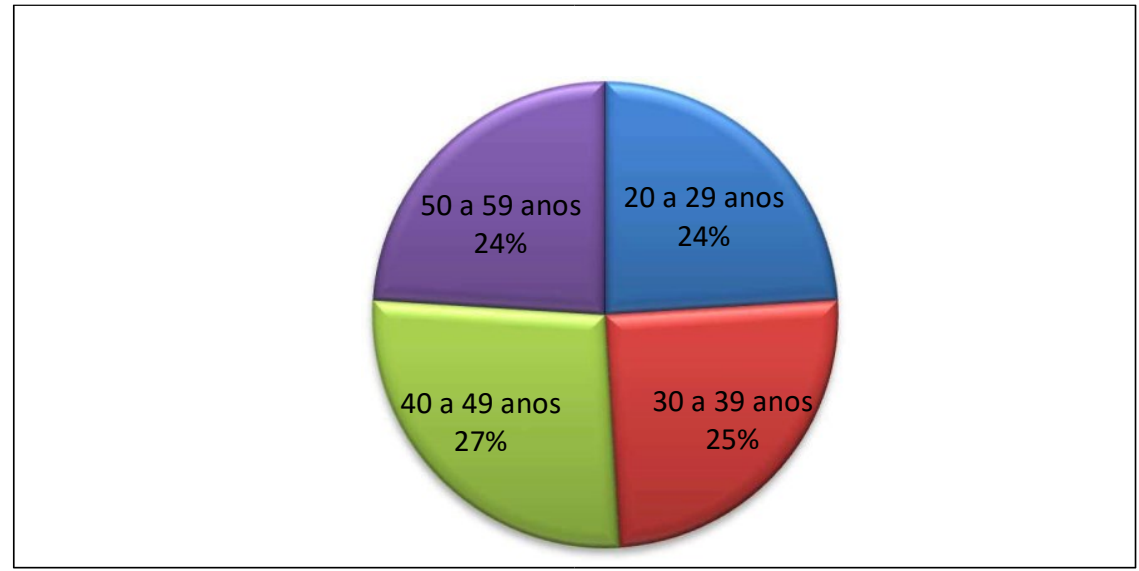

Fonte: Pesquisa direta, 2018.

Gráfico 2 - Uberlândia/MG: escolaridade dos homens entrevistados do Bairro Morada Nova, 2018

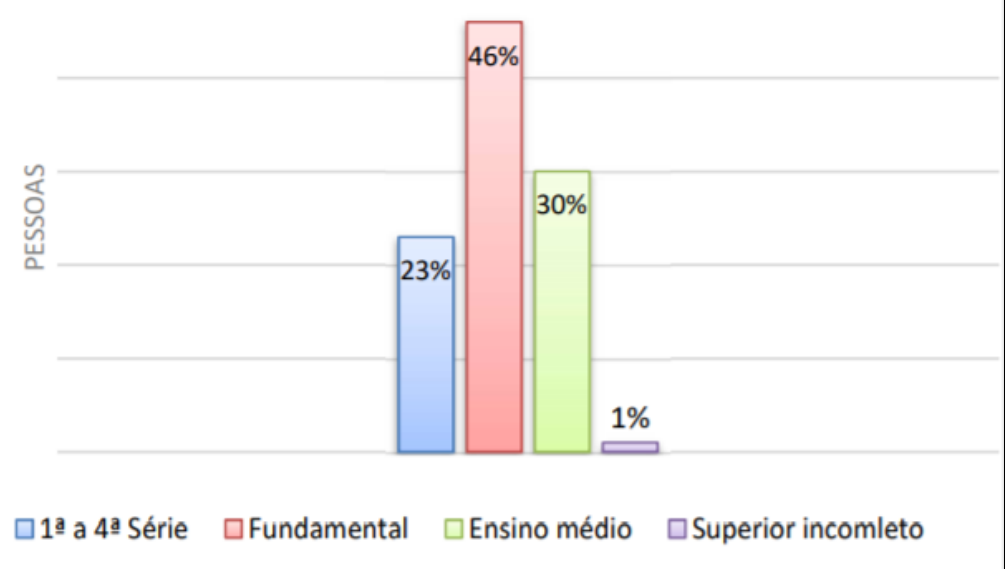

Fonte: Pesquisa direta, 2018.

Ao investigar os fatores que influenciam o homem a buscar por serviços de saúde e qual a sua expectativa sobre o serviço de saúde ofertado, todos os homens entrevistados responderam que tem a USF (Unidade de Saúde da Família) como principal meio de acesso a serviços de saúde do SUS. A população masculina pesquisada do bairro Morada Nova não dispõe de acesso à rede privada de saúde, deste modo todos os entrevistados são usuários da USF do bairro Morada Nova.

Ao indagar os homens sobre quando busca atendimento em serviços de saúde, verificou-se que $63 \%$ dos entrevistados informaram ter procurado por atendimento por serviços de saúde na USF em um período maior que 30 dias e menor que um ano. Enquanto $27 \%$ dos entrevistados estiveram na Unidade Básica de Saúde da Família em um intervalo menor de 30 dias; e 10\% dos entrevistados afirmaram que há mais de um ano não vão a USF, como demonstra os dados no Gráfico 3.

Assim, pôde-se constatar que $90 \%$ dos homens entrevistados procuraram por serviços de saúde na atenção primária em um período de um ano para a resolução de alguma necessidade de saúde. $O$ que dá a falsa impressão de que o homem é assíduo nas questões relativas à sua saúde, enquanto, na realidade, o homem busca por serviços de saúde quando apresenta alguma doença ou percebe uma piora de sua saúde. (COSTA-JUNIOR e MAIA, 2009).

DOl:http://dx.doi.org/10.14393/Hygeia16053468 $\quad$ Hygeia $\quad$ v.16 $\quad$ p. $105-120,2020$ página 111


Gráfico 3 - Uberlândia/MG: acesso a serviços de saúde na USF pelos homens entrevistados do Bairro Morada Nova, 2018

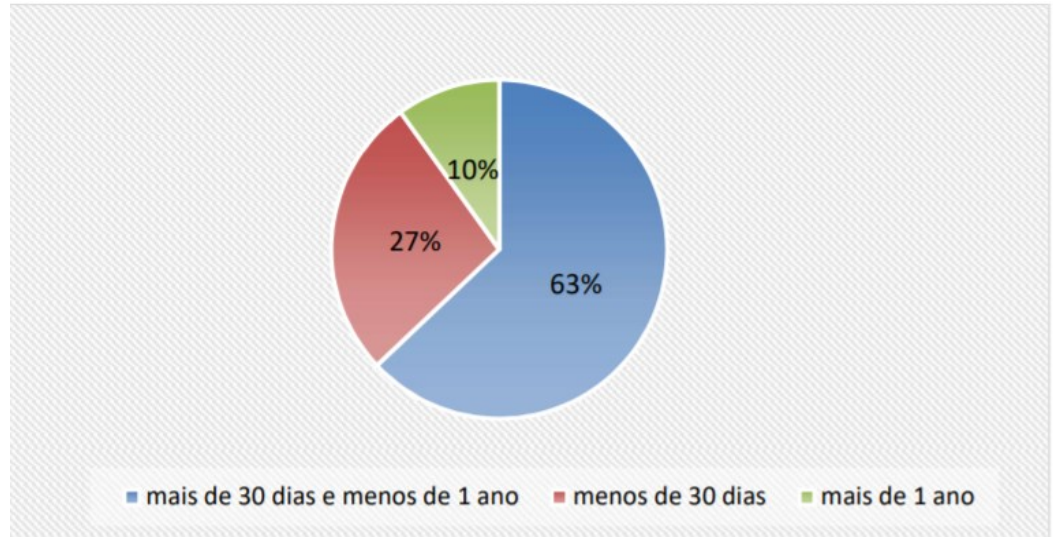

Fonte: Pesquisa direta, 2018

Os entrevistados que procuraram por atendimento para a resolução de agravos à saúde foram 49 homens, sendo os motivos diversos: emergência hipertensiva (pressão alta), diabetes descompensada, febre, diarreia, tosse, amigdalite, ferimentos, curativos, fraturas, dor repentina e transtorno mental. Já para a procura por serviços de prevenção à saúde foram 39 homens entrevistados passando por atendimento para os serviços de vacinação e exames de rotina (checkup/rotina). Os serviços de promoção à saúde foram os menos procurados, apenas dois homens buscaram atendimento e os procedimentos eram ligados ao planejamento familiar (vasectomia), como destaca a Tabela 1.

Tabela 1 - Uberlândia/MG: motivo para busca por serviços de saúde na atenção primária segundo os entrevistados do Bairro Morada Nova, 2018.

\begin{tabular}{lcc} 
Serviço de saúde procurado & $\begin{array}{c}\text { Número de } \\
\text { Ocorrências }\end{array}$ & \% de cada ocorrência \\
\hline Check-up/rotina & 29 & 30,45 \\
Dor repentina, ferimento, fratura & 14 & 14,70 \\
Vacinação & 12 & 12,60 \\
Febre, diarreia, tosse, amigdalite & 12 & 12,60 \\
Tratamento de dente & 09 & 9,45 \\
Pressão alta, diabetes & 04 & 4,20 \\
Curativos & 04 & 4,20 \\
Realizar vasectomia & 03 & 3,15 \\
Depressão, nervosismo, saúde mental & 03 & 3,15 \\
Doença cardíaca & 02 & 2,10 \\
Realização de cirurgia & 02 & 2,10 \\
Exame admissional & 01 & 1,05 \\
Exame de próstata & 00 & 0,0 \\
Problemas respiratórios & 00 & 0,0 \\
\hline \hline Total & 95 & $100 \%$ \\
\hline
\end{tabular}

Fonte: Pesquisa direta, 2018.

Os dados encontrados apontam para o fato da baixa procura por atendimentos de promoção à saúde e prevenção da doença, podendo ser explicado pela afirmação de Vieira et al. (2013), que a cultura masculina predominante no homem, associada à sensação de invulnerabilidade, afasta o homem da atenção primária, pois tal fato é visto como demonstração de fraqueza.

DOl:http://dx.doi.org/10.14393/Hygeia16053468 $\quad$ Hygeia $\quad$ v.16 $\quad$ p. $105-120,2020$ página 112


Um dado que pode comprovar essa citação é o fato de nenhum dos participantes alegar ter procurado a USF do bairro Morada Nova com a finalidade de realizar o exame de próstata. Cavalcante et al. (2014) também encontra situação semelhante no comportamento masculino para outras atividades de prevenção, ou seja, o homem é predisposto a fazer atividades de promoção a saúde, mas quando o tema é câncer de próstata, existe um constrangimento que induz o indivíduo a afastar-se dos serviços de atenção primária. Contudo, houve 29 homens entrevistados que se submeteram ao exame de rotina, e nesse exame é realizada a dosagem do antígeno prostático por amostra de sangue, que é o melhor método de prevenção do câncer de próstata e, quando necessário, é combinado o exame de toque retal (GUEDES e CALDEIRA JUNIOR, 2014).

Dos 90 homens que buscaram por atendimento na USF, 53 homens $(58,88 \%)$ tiveram a necessidade de prescrição de medicamento. Daqueles que buscaram por medicamentos na USF, 32 homens $(60,38 \%)$ conseguiram todos os remédios, 13 homens $(24,53 \%)$ conseguiram apenas uma parte dos medicamentos na USF e 8 homens $(15,10 \%)$ não obtiveram nenhum dos seus fármacos na USF (Gráfico 4). Portanto, $39,63 \%$ dos que precisavam de remédios não encontraram todos os medicamentos na USF, e isso comprova o que Vieria e Zucchi (2014) afirmam, ou seja, que o SUS prioriza alguns medicamentos em função do custo, segurança e eficácia. Mas muito ainda falta ao SUS para avançar e organizar, a fim de garantir o acesso a medicamentos para uma assistência de saúde integral.

\section{Gráfico 4 - Uberlândia/MG: acesso aos medicamentos após atendimento na USF pelos homens entrevistados do Bairro Morada Nova, 2018}

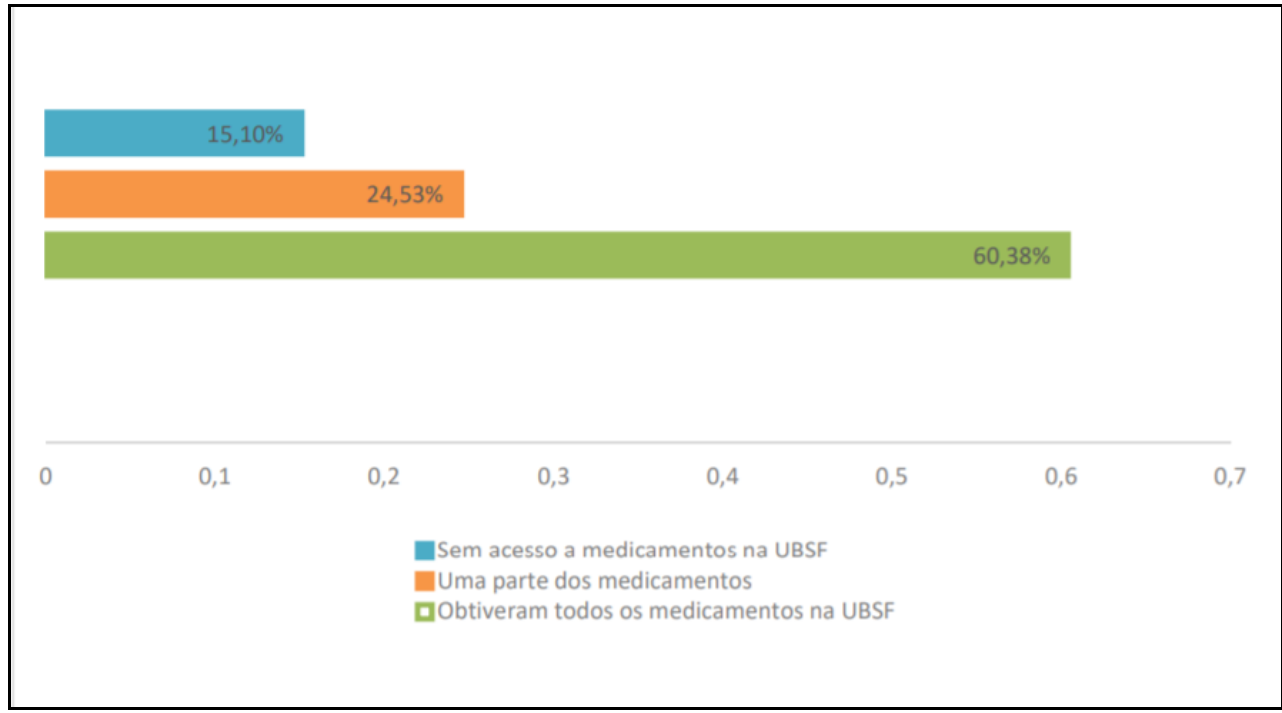

Fonte: Pesquisa direta, 2018.

Daqueles que não receberam os medicamentos prescritos na USF, $9,43 \%$ conseguiram os medicamentos por meio de doação da comunidade; entretanto, $5,67 \%$ não tiveram condições financeiras de comprar os medicamentos e, portanto, não tiveram acesso a nenhum dos fármacos prescritos. Os dados encontrados convergem com as afirmações de Nascimento et al. (2017), que diz que apesar da adoção de uma relação de medicamentos essenciais com financiamento público garantido pelo SUS, temos a oferta dos fármacos aquém das exigências da população. Assim, segue o desafio de garantir o acesso de medicamentos no campo da atenção básica, sendo que a baixa disponibilidade pode prejudicar os tratamentos já iniciados, o que eleva os gastos com atenção à saúde e compromete a qualidade de vida das pessoas.

Quanto ao tempo de espera daqueles que recorrem aos serviços da USF, para 60 homens entrevistados $(60 \%)$, o atendimento ocorreu entre 15 a 30 minutos; para 25 homens entrevistados (25\%), o tempo foi de 30 a 60 minutos e 5 homens disseram ter sido atendidos em menos de 15 minutos. Pode-se verificar que a maioria dos homens que foram a USF tiveram seu atendimento realizado em até uma hora, o que pode contribuir para que a demanda aumente, uma vez que não 
precisaram ficar o dia todo aguardando pela consulta médica. Esta tem sido uma das justificativas mais utilizadas pelos homens, em vários estudos, para não buscar o atendimento médico.

Sobre a qualidade do atendimento, 61 homens entrevistados (61\%) avaliaram o atendimento na USF como bom, 21 homens consideram muito bom, 7 homens avaliaram como regular e apenas 1 indivíduo $(1 \%)$ apontou o atendimento como ruim. Essa presteza no atendimento caracteriza resolutividade na assistência, o que aproxima aquele homem que não pode ausentar-se do trabalho. Deste modo, essas informações sobre a opinião do usuário é a melhor ferramenta de que dispomos sobre o que ainda pode ser feito para satisfazer as demandas desses usuários de serviços de saúde (ROSA, PELEGRINI e LIMA, 2011).

Dos 90 homens atendidos, apenas 20 foram encaminhados para outro serviço de saúde, ou seja, $22,22 \%$ não tiveram seus problemas de saúde resolvidos na USF. Essa condição de atender às exigências de saúde de um indivíduo e resolvê-lo até o nível de sua complexidade chamamos de resolutividade (BRASIL, 1990). Rosa e Labate (2005) indicam que a atenção primária à saúde consegue solucionar de $80 \%$ a $85 \%$ dos problemas de saúde da população, fato próximo do que foi demonstrado na USF local (Gráfico 5).

Gráfico 5 - Uberlândia/MG: efetividade da UBSF para resolução de necessidade de saúde, segundo os homens entrevistados do bairro Morada Nova, 2018

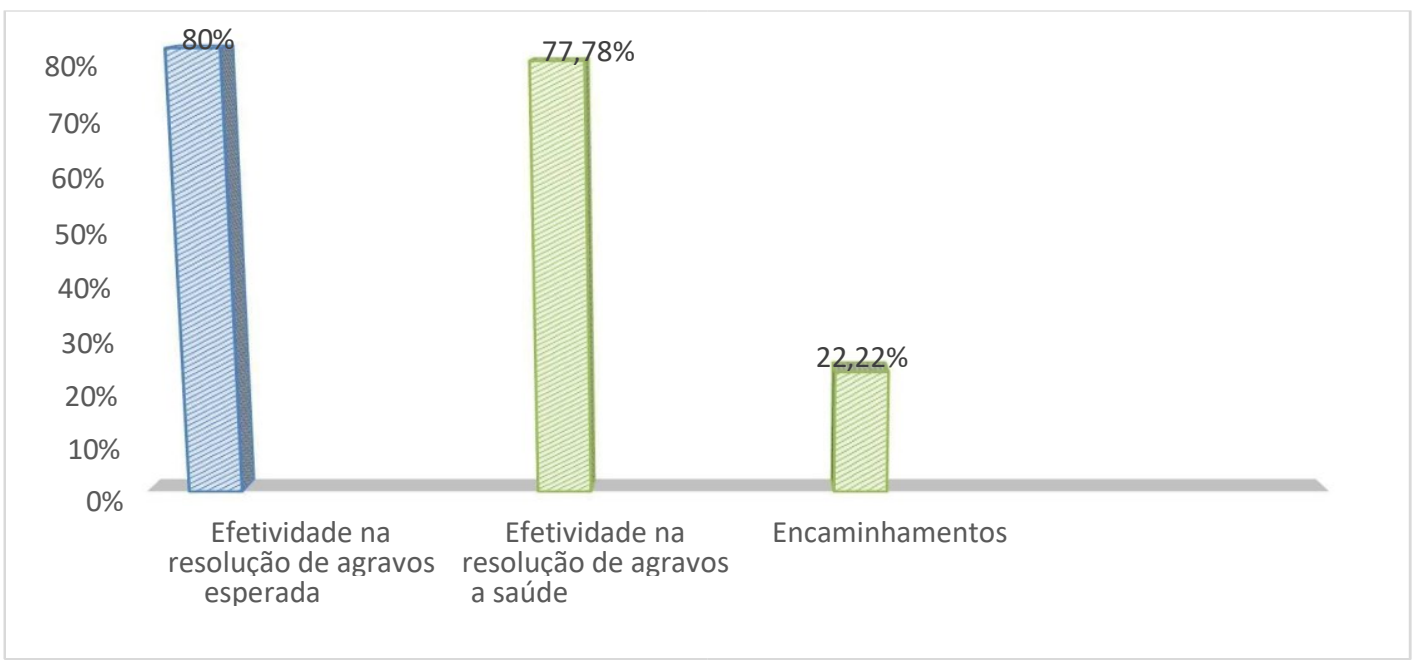

Fonte: Pesquisa direta, 2018.

De todos os homens entrevistados, apenas 10 não procuraram os serviços da USF no último ano. Destes apenas cinco tiveram algum agravo na saúde, porém não buscaram atendimento, uma vez que não consideraram a doença importante. Dos 5 homens entrevistados que apresentaram algum problema de saúde, 3 não fizeram nada para melhorar seu estado de saúde, um tomou remédio caseiro "Chá" e o outro se automedicou. Para Domingues et al. (2017), a automedicação é uma prática comum nos homens, sendo a dipirona a droga mais usada em associação com cafeína e o paracetamol. A Organização Mundial de Saúde (OMS, 1996) tornou público as diretrizes para avaliar os medicamentos usados na automedicação, mas, em países em desenvolvimento, a automedicação é um complemento ao sistema de saúde.

As questões relacionadas à adesão das ações de promoção da saúde e prevenção de doenças têm a finalidade de demonstrar os principais eventos na interação do homem com a oferta de serviços de prevenção e promoção da saúde na USF. Do universo de homens entrevistados, 77 deles $(77 \%)$ disseram que não foram convidados para consulta de rotina e 66 homens $(66 \%)$ não recordam de ser convidado para outra atividade sem ser consulta na USF (Gráfico 6). Das situações possíveis para esse fato, é que o homem compreende o aspecto biológico do processo de adoecimento e valoriza o processo de tratamento a medicação, dando menor importância a medidas que proporcionam à promoção e à prevenção, como mecanismo de atender às necessidades pessoais de saúde (MARIN, 2013). 
Do público pesquisado, 34 homens (34\%) receberam convite para outra atividade sem ser consulta na USF; 23 homens (23\%) foram convidados a comparecer à consulta de rotina e 30 homens $(30 \%)$ participaram de grupos educativos de prevenção a diabetes e hipertensão arterial. Duas pessoas foram a palestras sobre prevenção do câncer de próstata e dois homens em reuniões do Conselho de Saúde do Setor Oeste ${ }^{2}$ na USF.

Gráfico 6 - Uberlândia/MG: participação do homem nas campanhas de promoção e prevenção a saúde do homem segundo os entrevistados do Bairro Morada Nova, 2018

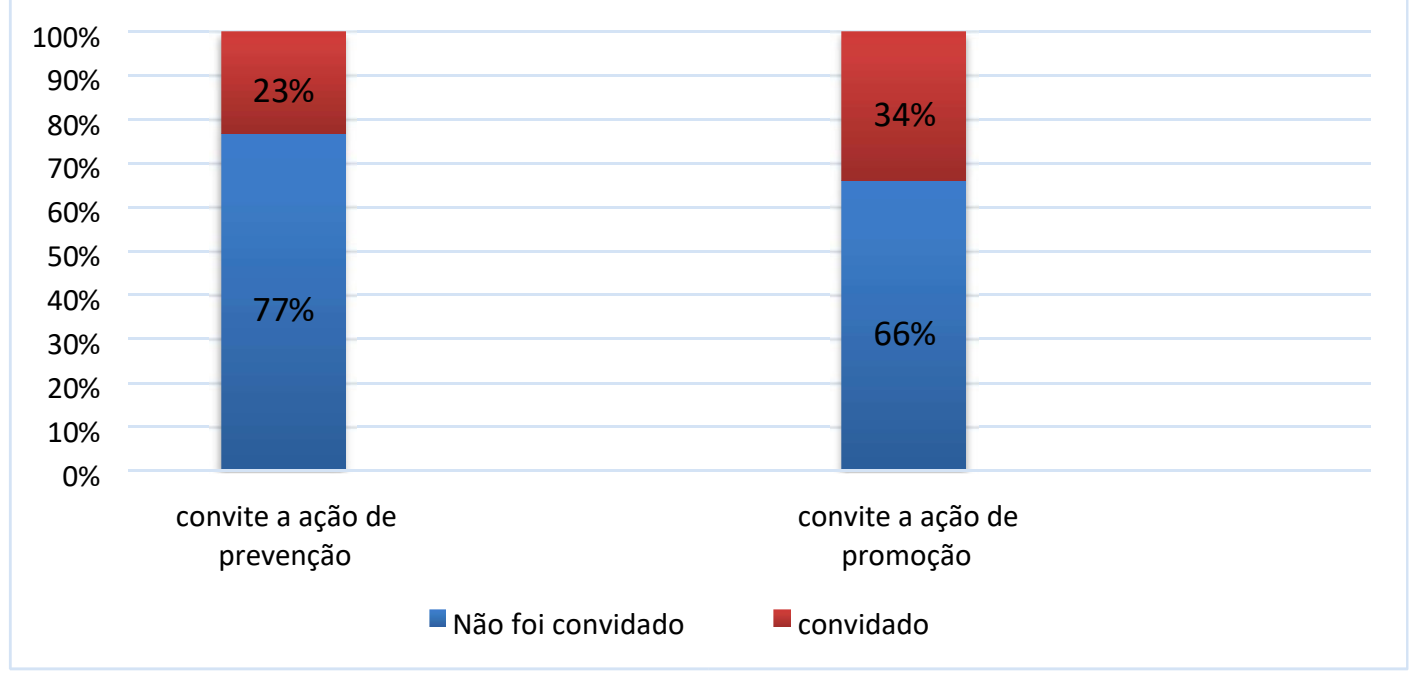

Fonte: Pesquisa direta, 2018.

Quanto ao conhecimento sobre a existência de alguma atividade direcionada aos homens na USF, apenas 20 entrevistados $(20 \%)$ tinham conhecimento. E, quando indagados se participariam de alguma atividade direcionada ao público masculino, 84 dos entrevistados (84\%) responderam que não participariam. Ao passo que 16 entrevistados (16\%) responderam que poderiam participar de alguma atividade deste fim (Gráfico 7). Esse cenário vai de acordo com Silva et al. (2010), que esclarecem que o homem usa das responsabilidades de provedor do lar e da família como um empecilho para a participação nas ações de promoção à saúde.

Uma condição encontrada foi que, quando perguntados sobre o desejo de que existisse alguma atividade voltada aos homens, 97 dos entrevistados argumentaram que gostaria de que serviços ou atividades voltadas especificamente para o homem fossem disponibilizados na USF Morada Nova em horário e dia oportuno. Dos entrevistados, 89 homens (89\%) asseguraram sentir-se à vontade para falar da sua saúde com qualquer profissional da USF, independente se for homem ou mulher. Dos que se sentem constrangidos de falar sobre o tema, que totalizam 11 homens (11\%), destes 07 homens preferem falar sobre a sua saúde com homens e 03 com mulher e apenas 01 alegou timidez. A situação encontrada é comentada por Figueiredo (2005), pois o vínculo estabelecido entre o homem e os serviços de saúde, associado à sensibilidade dos profissionais sobre as carências do gênero masculino e as demandas trazidas pelos homens usuários dos serviços de saúde, repercute positivamente na interação entre os profissionais independe de seu gênero, com o público masculino.

\footnotetext{
${ }^{2}$ O Conselho de Saúde do Setor Oeste representa a participação popular na elaboração de políticas e sugestões de ações em saúde para a população do setor oeste de Uberlândia/MG 
Gráfico 7 - Uberlândia/MG: participação em alguma atividade relacionada à saúde do homem, pelos entrevistados do Bairro Morada Nova, 2018

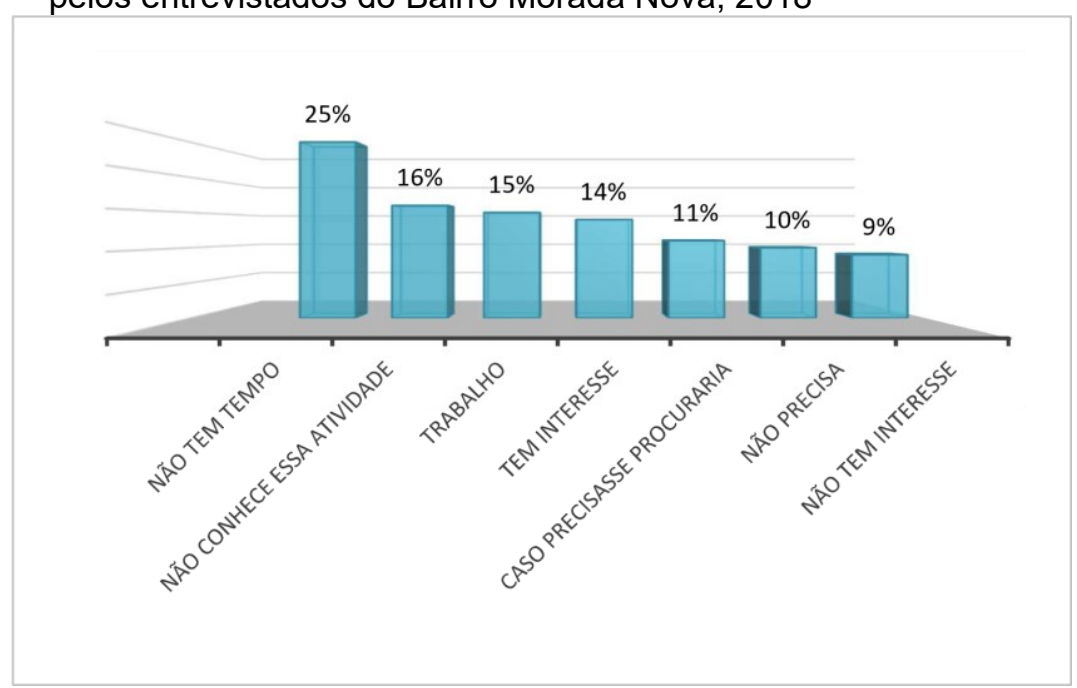

Fonte: Pesquisa direta, 2018

Quanto à participação do homem nas atividades de promoção e prevenção, apenas $30 \%$ da amostra participaram de atividades que não sejam consulta, voltadas para a promoção da saúde. Apenas $20 \%$ sabiam da existência de alguma atividade voltada à promoção a saúde do homem. Tais fatos apontam a necessidade de trabalhar a divulgação das atividades ofertadas nas USF, e até mesmo a importância de estender o horário das atividades da USF para o horário do trabalhador.

As justificativas da recusa em participar de ações de saúde direcionadas do homem persiste como as mesmas respostas já amplamente divulgadas na literatura: "não tenho tempo", "não tenho interesse", "trabalho", "desconheço de alguma atividade voltada para ao homem na USF". Contudo, deve-se insistir na divulgação de campanhas da unidade de saúde em escolas, igrejas, feiras locais, locais de grande aglomeração de pessoas ou seja, são essenciais ações perenes focadas nas necessidades do homem e, por que não, eventos em finais de semana, propiciar o horário estendido compreendido como horário do trabalhador a partir das 17 horas até às 22 horas e consultas/atendimento com hora marcada.

No entanto $97 \%$ dos homens manifestaram o desejo da existência de atividades direcionadas exclusivamente ao público masculino na USF. A interação dos profissionais de saúde com o seu público e o fácil acesso a serviços de saúde possibilitam que o homem se sinta à vontade de falar de sua situação de saúde com qualquer profissional. A capacitação da equipe de saúde deve ser constante, a fim de compreender as reais necessidades do público masculino e interpretar as mudanças indispensáveis ao bom atendimento, e, assim, inserir o homem na atenção primária.

\section{CONSIDERAÇÕES FINAIS}

Este trabalho foi uma oportunidade de interrogar os homens e compreender um pouco de suas necessidades, entraves e as estratégias para a promoção da saúde frente aos obstáculos encontrados. De acordo com a pesquisa realizada, os homens entrevistados confirmaram ter no SUS o único e principal meio de obter assistência à saúde. A concentração de indivíduos é maior na faixa etária dos 30 a 49 anos e decresce a partir dos 50 anos, por isso, justifica trabalhar a prevenção e a promoção da saúde a partir dos 20 anos para obter uma população com melhores condições de saúde. O nível de escolaridade não influenciou na adesão do homem nos serviços de atenção primária.

O homem não acredita na probabilidade de perecer ante a um quadro de doença, já que o próprio status quo do modelo social vigente, que o coloca como pilar principal de seu grupo social, sustenta essa posição e the dá uma falsa sensação de imponência. Enquanto, na realidade, o homem adentra os serviços de saúde com a finalidade de alívio de sintomas ou com a sua saúde agravada, 
necessitando maior tempo de tratamento e recursos financeiros. Portanto, observa-se o sentimento de invulnerabilidade com relação à prevenção e promoção da saúde.

Nota-se a persistência do preconceito, principalmente, sobre ações relacionadas ao câncer de próstata. Nos homens entrevistados, uma fração da amostragem utilizou a dosagem do antígeno prostático como método auxiliar para prevenção do câncer de próstata, enquanto o exame de toque da próstata é negligenciado, apesar da facilidade de acesso a USF.

A assistência farmacêutica é importante, pois visa garantir o uso racional e seguro de medicamentos o que contribui para a cura e/ou controle da doença. No estudo pode-se verificar que houve a falta de alguns dos medicamentos prescritos. Das causas responsáveis cita-se as questões de logística, o esgotamento de aporte financeiro estatal para compra de medicamentos, ou a questão da escolha do profissional de saúde, ao optar, ou não, por medicamentos padronizados na rede municipal de saúde para tratamentos das doenças, daí um percentual maior, ou menor de pessoas que precisaram adquirir medicamentos fora da rede municipal de saúde.

Quando a assistência à saúde se demonstra insuficiente para atender às necessidades da população, torna-se comum a automedicação e o uso de terapia com plantas medicinais para tratamento de algum agravo, pois são meios baratos de tratamento ou alívio de sintomas. No estudo realizado, a automedicação e o uso de ervas medicinais apareceram de forma discreta.

A eficácia da USF pode ser aferida, quando se verifica que esta consegue atender aos problemas de saúde da população dentro do seu nível de competência. Na pesquisa observou-se que o modo operante da USF tem como foco o tratamento de doença. Ainda assim, apesar dessa característica curativista nas USF, encontrou-se situação satisfatória na resolução dos agravos no Morada Nova. A facilidade de acesso a serviços de saúde em Uberlândia aponta para uma maior eficiência da USF no Bairro Morada Nova.

O tempo de atendimento é muito importante, pois este é um dos fatores que colaboram para afastar, ou aproximar, o homem dos serviços de saúde. Na USF do bairro Morada Nova, a maioria dos entrevistados foram atendidos dentro de um período de 30 minutos, e quanto à satisfação nesse atendimento, este foi aferido como bom/muito bom. A percepção dos profissionais de saúde sobre as carências de saúde de uma população aumenta a confiabilidade do público atendido pela USF e, consequentemente, o cliente/paciente satisfeito evidencia uma adesão terapêutica melhor, e melhores respostas ao tratamento, com melhores condições de saúde para a referida população.

No estudo realizado, verificou-se pela percepção dos entrevistados que não se tem o costume e o hábito de procurar por oferta de serviços de prevenção e promoção da saúde. $O$ homem não participa das atividades de promoção e prevenção, não conhece as atividades voltadas a saúde, do homem. O homem, quando convidado a participar de atividades de promoção à saúde aponta as seguintes justificativas: "não tenho tempo", "não tenho interesse", "trabalho", "desconheço de alguma atividade voltada para ao homem na USF". Contudo deve-se insistir na divulgação de campanhas da unidade de saúde em escolas, igrejas, feiras locais, locais de grande aglomeração de pessoas, ou seja, são imprescindíveis ações perenes focadas nas necessidades do homem e porque não, eventos em finais de semana, propiciar o horário estendido, compreendido como horário do trabalhador, a partir das 17 horas até às 22 horas e consultas/atendimento com hora marcada.

A maioria dos homens pesquisados citaram que gostariam que houvesse alguma atividade específica para o homem. Tampouco o homem apresenta-se constrangido para conversar de seus problemas de saúde com qualquer profissional independente do sexo. A boa interação entre profissional de saúde e paciente converge para uma facilidade do homem em expressar-se com o profissional seja qual for o sexo.

O homem é mais suscetível a agravos de causas externas, tem participação pífia nas ações de prevenção e promoção de doenças, tem hábitos de riscos, como uso de bebidas alcoólicas, tabagismo, e procura por tratamento de sua saúde para tratar sintomas, ou, quando da doença instalada. A precisão do homem de pertencer a um grupo, que tem como hábitos/costumes arraigados em sua cultura, tais situações de risco, torna difícil a implementação de práticas de saúde, porque esse é seu estilo de vida. Ora, se o estilo de vida não é criado pelo homem, mas sim incorporado pelo homem pela sua cultura, antes de querer mudar os hábitos no homem, é forçoso compreender e, portanto, é interessante criar uma nova cultura, a cultura de cuidar da saúde e, por consequência, a mudança de hábitos. 
A capacitação da equipe de saúde deve ser constante a fim de compreender as reais necessidades do público masculino e interpretar as mudanças pertinentes ao bom atendimento, e, assim, inserir o homem na atenção primária.

Este estudo é de relevância para a ciência, pois aponta que, mesmo após 10 anos do incremento da política nacional de saúde do homem, este ainda carece de serviços de promoção e prevenção de doenças, e os serviços de APS ainda não conseguem inserir o homem totalmente em seu rol e ações. Esse é um assunto complexo, espera-se que os resultados desta pesquisa possam subsidiar a organização dos serviços de saúde, e o planejamento de ações na saúde direcionadas ao público masculino, para que o PNASH seja literalmente integrado à atenção básica, com reflexo positivo no perfil da morbimortalidade do homem no Brasil.

\section{REFERÊNCIAS}

AITH, F. A. Marcos legais da promoção da saúde no Brasil. Revista de Medicina, São Paulo, v. 92, n. $2, \quad$ p. $148-154, \quad$ jun. 2013. Disponível em: http://www.revistas.usp.br/revistadc/article/view/79977/83903. Acesso em: 05 jun. 2018. https://doi.org/10.11606/issn.1679-9836.v92i2p148-154

ALVES, R. F. et al. Gênero e saúde: o cuidar do homem em debate. Psicol. teor. prat., São Paulo, v. 13, n. 3, p. 152-166, dez. 2011. Disponível em: http://pepsic.bvsalud.org/scielo.php?script=sci_arttext\&pid=S151636872011000300012\&Ing=pt\&nrm=iso. Acesso em: 18 abr. 2019.

BRASIL. Lei 8.080, de 19 de setembro de 1990. Dispõe sobre as condições para a promoção, proteção e recuperação da saúde, a organização e o funcionamento dos serviços correspondentes e dá outras providências. Diário Oficial da União, Brasília, DF, 20 set. 1990. Disponível em: http://www.planalto.gov.br/ccivil_03/LEIS/L8080.htm. Acesso em: 15 set. 2018.

BRASIL. Ministério da Saúde. Portaria $n^{\circ}$ 692, de 25 de março de 1994. Programa de agentes comunitários e de saúde da família: PACS/PSF. Diário Oficial da União, Brasília, DF, 29 mar. 1994. Disponível em: http://sna.saude.gov.br/legisla/legisla/prog_pacs_psf/. Acesso em: 10 set. 2018.

BRASIL. Ministério da Saúde. Portaria $n^{\circ} 2.203$, de 5 de novembro de 1996. Norma operacional básica do sistema único de saúde nob-sus 01/96. Diário Oficial da União, Brasília, DF, 06 nov. 1996. Disponível em: http://bvsms.saude.gov.br/bvs/publicacoes/n ob.pdf. Acesso em: 25 out. 2018.

BRASIL. Ministério da Saúde.Coordenação-Geral de Documentação e Informação. O Sistema Público de Saúde Brasileiro. Brasília, Ministério da Saúde, (2002a). 44p. Disponível em: http://bvsms.saude.gov.br/bvs/publicacoes/sistema_saude.pdf. Acesso em: 22 abr. 2019.

BRASIL. Ministério da Saúde. Portaria $\mathrm{n}^{\circ}$ 373, de 27 de fevereiro de 2002. Norma Operacional da Assistência à Saúde 01/02. Diário Oficial da União, Brasília, DF, v. 139, n. 40, fev. 2002b, p. 52 68. Disponível em: http://bvsms.saude.gov.br/bv s/saudelegis/gm/2002/prt0373_27_02_2002.html. Acesso em: 20 fev. 2019.

BRASIL. Ministério da Saúde. Portaria Interministerial $n^{\circ} 153$, de 13 de fevereiro de 2004. Programa de saúde do trabalhador. Diário Oficial da União, Brasília, DF, 10 fev. 2004a. Disponível em: https://www.nescon.medicina.ufmg.br/biblioteca/imagem/01 85.pdf. Acesso em: 18 set. 2018.

BRASIL. Ministério da Saúde. Secretaria de Atenção à Saúde. Departamento de Ações Programáticas Estratégicas. Política nacional de atenção integral à saúde da mulher: plano de ação 2004-2007. Brasília: Ministério da Saúde, 2004b. 48p.

BRASIL. Ministério da Saúde. Secretaria-Executiva. Núcleo Técnico da Política Nacional de Humanização. Humaniza SUS: Política Nacional de Humanização - A humanização como eixo norteador das práticas de atenção e gestão em todas as instâncias do SUS. Brasília: Ministério da Saúde, 2004c. 20p.

BRASIL. Decreto $n^{\circ} 5090$, de 20 de maio de 2004. Programa Farmácia Popular do Brasil. Brasília, DF, março de 2017. Diário Oficial da União, Brasília, DF, 21 maio. 2004d. Disponível em: DOl:http://dx.doi.org/10.14393/Hygeia16053468 $\quad$ Hygeia $\quad$ v.16 $\quad$ p. $105-120,2020$ página 118 
http://www.planalto.gov.br/ccivil_03/_ato2004-2006/20 04/decreto/d50 90.htm. Acesso em: 25 out. 2018.

BRASIL. Ministério da Saúde. Portaria $n^{\circ}$ 399/GM, de 22 de fevereiro de 2006. Diário Oficial da União, Brasília: Ministério da Saúde, 23 fev 2006. Seção 1, p.43-51

BRASIL. Ministério da Saúde. Portaria $n^{\circ} 1944$, de 27 de agosto de 2009. Diário Oficial da União, Brasília, DF, 28 ago. 2009a. Disponível em: http://bvsms.saude.gov.br/bvs/saude legis/gm/2009/prt1944_27_08_2009.html. Acesso em: 06 set. 2018.

BRASIL. Ministério da Saúde. Secretaria de Atenção à Saúde. Departamento de Ações Programáticas e Estratégicas. Política Nacional de Atenção Integral à Saúde do Homem: princípios e diretrizes. Brasília: Ministério da Saúde, 2009b. 92p.

BRASIL. Ministério da Saúde. Fundação Osvaldo Cruz. Fortalecimento da Política Nacional de Atenção Integral à Saúde do Homem (PNAISH): compromisso versus ação na atenção básica. Rio de Janeiro: Instituto Nacional de Saúde da Mulher, da Criança e do Adolescente Fernandes Figueira, 2013. 89p.

CARNEIRO, L. M. R. et al. Atenção integral à saúde do homem: um desafio na atenção básica. Rev. Bras. Prom. Saúde, Fortaleza, v. 29, n. 4, p. 554-563, out./dez. 2016. https://doi.org/10.5020/18061230.2016.p554

CAVALCANTI, J. R. D. et al. Assistência Integral a Saúde do Homem: necessidades, obstáculos e estratégias de enfrentamento. Esc. Anna Nery, Rio de Janeiro, v. 18, n. 4, p. 628-634, dez. 2014.

COSTA-JÚNIOR, F. M.; MAIA, A. C. B. Concepções de homens hospitalizados sobre a relação entre gênero e saúde. Psicologia: Teoria e Pesquisa. Instituto de Psicologia, Universidade de Brasília (UnB), v. 25, n. 1, p. 55-63, 2009. Disponível em: http://hdl.handle.net/11449/288 59. Acesso em: 20 abr. 2019. https://doi.org/10.1590/S0102-37722009000100007

COUTO, M. T. et al. O homem na atenção primária à saúde: discutindo (in)visibilidade a partir da perspectiva de gênero. Interface, Botucatu, v. 14, n. 33, p. 257-270, jun. 2010. Disponível em: http://www.scielo.br/scielo.php?pid=S1414- $32832010000 \quad$ 200003\&script=sci_abstract\&tlng=pt. Acesso em: 18 jan. 2019. https://doi.org/10.1590/S1414-32832010000200003.

DOMINGUES, P. H. F. et al. Prevalência e fatores associados à automedicação em adultos no Distrito Federal: estudo transversal de base populacional. Epidemiol. Serv. Saúde, Brasília, v. 26, n. 2, p. 319-330, jun. $2017 . \quad$ Disponível em: http://scielo.iec.gov.br/scielo.php?script=sci_arttext\&pid=S1679-

49742017000200319\&lng=pt\&nrm=iso. Acesso em: 18 mar. 2019. https://doi.org/10.5123/S167949742017000200009

DUARTE, S. J.; OLIVEIRA, J. R.; SOUZA, R. R. A Política Saúde do Homem e sua operacionalização na Atenção Primária à Saúde. Revista Eletronica Gestão \& Saúde, v. 3, n. 1, p. 308-317, jan. 2012. Disponível em: http://periodicos.unb.br/index.php/rgs/article/view /24296. Acesso em: 10 jun. 2018. https://doi.org/10.18673/gs.v3i1.24296

FIGUEIREDO, W. Assistência à saúde dos homens: um desafio para os serviços de atenção primária. Ciênc. saúde coletiva, Rio de Janeiro, v. 10, n. 1, p. 105-109, mar. 2005. Disponível em: http://www.scielo.br/scielo.php?script=sci_arttext\&pid=S1413-8123200500

0100017\&lng=en\&nrm=iso. Acesso em: 20 abr. 2019. https://doi.org/10.1590/S1413$\underline{81232005000100017}$

FUCHS, A. M. S.; FRANÇA, N. M.; PINHEIRO, M. S. F. Guia para normalização de publicações técnico-científicas. Uberlândia: EDUFU, 2013. 286p. https://doi.org/10.14393/EDUFU-978-85-7078342-4

GUEDES, G. A.; CALDEIRA JUNIOR, A. M. As Vantagens da Utilização do Exame Antígeno Prostático Específico (PSA) no Diagnóstico do Câncer de Próstata. Revista de Divulgação Científica Sena Aires, Valparaíso de Goiás, v. 1, p. 89-96, jan./jun. 2014. 
GOMES, R.; NASCIMENTO, E. F.; ARAUJO, F. C. Por que os homens buscam menos os serviços de saúde do que as mulheres? As explicações de homens com baixa escolaridade e homens com ensino superior. Caderno Saúde Pública, Rio de Janeiro, v. 23, n. 3, p. 565 - 574, mar. 2007. Disponível em: http://www.scielo.br/scielo.php?pid=S0102311X20070003 0001 $5 \&$ scipt=sci_abstract\&tlng =pt. Acesso em: 08 abr. 2017. https://doi.org/10.1590/S0102$\underline{311 \times 2007000300015}$

LIMA, S. C.; SANTOS, F. O. Promoção da saúde e redes comunitárias para a construção de territórios saudáveis. Uberlândia: Universidade Federal de Uberlândia, 2018. 176p.

LUIZ, R. R.; MAGNANINI, M. M. F. A lógica da determinação do tamanho da amostra em investigações epidemiológicas. Cadernos de Saúde Coletiva, Rio de Janeiro, v. 8, n. 2, p. 928, ago./dez. 2000.

MARIN, M. J. S. et al. Conhecendo os motivos da não adesão às ações educativas em saúde. Revista Mineira de Enfermagem, Belo Horizonte, v. 17, n. 3, p. 500-509, jul./set. 2013. Disponível em: http://www.reme.org.br/artigo/detalhes/668. Acesso em: 27 out. 2018.

MONKEN, M.; BARCELLOS, C. Vigilância em saúde e território utilizado: possibilidades teóricas e metodológicas. Cad. Saúde Pública, Rio de Janeiro, v. 21, n. 3, p. 898-906, 2005. https://doi.org/10.1590/S0102-311X2005000300024

MOURA, E. Perfil da situação de saúde do homem no Brasil. Rio de Janeiro: Fundação Oswaldo Cruz, Instituto Fernandes, 2012. 128p.

NASCIMENTO, R. C. R. M. et al. Disponibilidade de medicamentos essenciais na atenção primária do Sistema Único de Saúde. Rev. Saúde Pública, São Paulo, v. 51, supl. 2, 2017. Disponível em: http://www.scielo.br/scielo.php?script=sci_arttext\&pid=S0 03489102017000300303\&lng=pt\&nrm=iso. Acessos em: 18 mar. 2019.

OLIVEIRA, M. M. et al. A saúde do homem em questão: busca por atendimento na atenção básica de saúde. Ciência \& Saúde Coletiva, v. 20, n. 1, 2015, p. 273-285. Disponível em: http://gogalegroup.ez34.periodicos.capes.gov.br/ps/i.do?\&id=GALE|A399412342\&v=2.1\&u=capes\&i $\mathrm{t}=\mathrm{r} \& \mathrm{p}=\mathrm{AONE} \& \mathrm{sw}=\mathrm{w \#}$. Acesso em: 22 mar. 2019.

RODRIGUES, M. E. V. et al. O cuidado à saúde da população masculina em tempos de Política Nacional de Atenção Integral à Saúde do Homem: o que eles falam. Cultura de los Cuidados, v. 19, n. 41, 2015. Disponível em: http://dx.doi.org/10.14198/cuid.2015.41. 16. Acesso em: 11 jun. 2018. https://doi.org/10.14198/cuid.2015.41

ROSA, W. D. A. G.; LABATE, R. C. Programa Saúde da Família: a construção de um novo modelo de assistência. Revista Latino-Americana de Enfermagem, Ribeirão Preto, v. 13, n. 6, p. 1027-1034, 2005. https://doi.org/10.1590/S0104-11692005000600016

ROSA, R. B.; PELEGRINI, A. H. W.; Lima, M. A. D. S. Resolutividade da assistência e satisfação de usuários da estratégia saúde da família. Rev. Gauch. Enferm., Porto Alegre, v. 32, n. 2, p. 345-51, 2011. https://doi.org/10.1590/S1983-14472011000200019

SILVA, M. E. D. C. et al. Resistência do homem às ações de saúde: percepção de enfermeiras da Estratégia Saúde da família. NOVAFAPI, Teresina, v. 3, n. 3, p. 21-5, 2010.

UBERLÂNDIA. Prefeitura Municipal de Uberlândia, 2014. Disponível em: http://www.uberlandia.mg.gov.br/print.php?id=7442. Acesso em: 10 out. 2018.

VIEIRA, K. L. D. et al. Atendimento da população masculina em Unidade Básica de Saúde da Família: motivos para a (não) procura. Esc. Anna Nery, Rio de Janeiro, v. 17, n. 7, p.120-127, jan./mar. 2013. https://doi.org/10.1590/S1414-81452013000100017 